\title{
COMPREENDENDO O ALCOOLISMO NA FAMÍLIA
}

\author{
Understanding Alcoholism in the Family Context \\ Comprendiendo el Alcoholismo en la Família
}

Carmen Lúcia Alves Filizola

Sofia Cristina lost Pavarini

\author{
Camila de Jesus Perón \\ José Fernando Petrilli Filho
}

Mariana Montagner Augusto do Nascimento

\section{Resumo}

0 alcoolismo é um sério problema de saúde pública. 0 seu tratamento é complexo e a inclusão da família tem sido enfatizada. Esta pesquisa teve como objetivo identificar a estrutura, as relações, a rede de suporte e a vivência de famílias diante do alcoolismo. A coleta de dados foi realizada através de entrevistas semi-estruturadas com cinco famílias de alcoolistas de uma Unidade de Saúde da Família. Verificamos que o alcoolismo constituiu-se no maior problema para as famílias que demonstram pouco conhecimento sobre o tema. Entre as maiores dificuldades encontramos a violência sofrida pelos familiares. As relações familiares são conturbadas. A maioria das famílias isola-se evitando falar do alcoolismo com outros. Portanto, a rede de supor te social seria fundamental. Ao analisá-la constatamos a precariedade de recursos públicos, o desconhecimento dos existentes e a não utilização de Grupos de Apoio pelas famílias.

Palavras-chave: Alcoolismo. Família. Apoio Social.

\begin{abstract}
Alcoholism is a serious problem for the public health. Its treatment is complex and the inclusion of the patient's family has been emphasized. The objective of this research was to identify the structure, relationships, support network and experiences of families before the alcoholism. The data collection was made through semi-structured interviews with five alcoholics' families of a Family Health Unit. We verified that alcoholism composes the major problem for these families that demonstrated not much knowledge about the topic. Among the major difficulties we found the violence suffered by the relatives. The family relations are disturbed. Most families avoid talking about alcoholism with other people. Therefore, the social support network is vital. Analyzing that, we verified the precariousness of the public resources, the unawareness of the existing resources and the non-utilization of the Support Groups by families.
\end{abstract}

\section{Resumen}

El alcoholismo es un serio problema de salud pública. Su tratamiento es complejo y la inclusión de la familia ha sido enfatizada. Esta investigación tuvo como objetivo identificar la estructura, las relaciones, la red de suporte y la vivencia de la familias perante al alcoholismo. La recolección de datos fue realizada a través de entrevistas semiestructuradas con cinco familias de alcohólicos de una Unidad de Salud de Familia. Verificamos que el alcoholismo se constituyó como mayor problema para las familias que demuestran poco conocimiento sobre el tema. Dentro de las mayores dificultades encontramos la violencia sufrida por los familiares. Las relaciones familiares son conturbadas. La mayoría de las familias evita hablar del alcoholismo con otros se alejando. Por esto, la red de suporte social seria fundamental. Al analizarla constatamos la precariedad de recursos públicos, el desconocimiento de los existentes y la no utilización de Grupos de Apoyo por las familias. 
INTRODUÇÃO

0 alcoolismo é um sério problema de saúde pública. Segundo o Ministério da Saúde, o uso do álcool impõe às sociedades de todos os países uma carga global de agravos indesejáveis e extremamente dispendiosos, que acometem os indivíduos em todos os domínios de sua vida'.

$01^{\circ}$ Levantamento Domiciliar sobre 0 uso de Drogas Psicotrópicas no Brasil indica uma prevalência do uso do álcool na vida de $68,7 \%$ sendo ela maior para o sexo masculino $(17,1 \%)$ do que para o feminino $(5,7 \%)$. No total, há uma estimativa de $11,2 \%$ de dependentes de bebidas alcoólicas nas 107 maiores cidades do Brasil'.

Atualmente, o termo "alcoolismo" vem sendo substituído por Síndrome de Dependência do Álcool (SDAS), a qual se diferencia por ser entendida como um processo no qual a pessoa ficaria gradualmente dependente do álcool, eliminando a visão dicotômica de "tudo ou nada" implícita no termo alcoolismo ${ }^{3}$.

Os prejuízos trazidos pelo uso excessivo de álcool são inúmeros. Entre eles ressaltam-se as alterações comportamentais da pessoa que faz uso e abuso do álcool levando, na maioria das vezes, à desestruturação familiar, a gastos excessivos com tratamentos médicos e internações hospitalares, a elevado número de acidentes de trânsito com pessoas alcoolizadas, violência urbana e mortes prematuras ${ }^{2}$.

Sobre os efeitos do alcoolismo na família, estudos demonstram que viver em um "ambiente alcoolista" afeta negativamente os descendentes de alcoolistas e que, para cada alcoolista, cinco ou seis pessoas da família são afetadas ${ }^{4}$. Problemas familiares como desavenças, falta de credibilidade e desconfianças são sentimentos despertados nas pessoas que já passaram pela experiência de ter um dependente e, quando há um dependente na família, todos adoecem ${ }^{5}$.

0 tratamento do alcoolismo é complexo e, dependendo da necessidade do usuário e do recurso disponível, pode ocorrer tanto em serviços especializados como nos CAPS ad (álcool e drogas), quanto em serviços da atenção básica, ambulatórios, hospitais e grupos de apoio da comunidade'.

A inclusão da família no tratamento tem sido enfatizada como imperiosa no processo terapêutico desses pacientes ${ }^{1,6}$. 0 Ministério da Saúde propõe como diretriz para o atendimento no CAPS ad, além do oferecimento de cuidado aos familiares de usuários do serviço, um trabalho junto a usuários e familiares que aborde os fatores de proteção para 0 uso de substâncias psicoativas e a diminuição do estigma e preconceito em relação às referidas substâncias, mediante atividades de cunho preventivo/educativo ${ }^{1}$.
Diante da magnitude do problema, do reconhecimento de suas conseqüências na família e da importância da inclusão da família no processo de tratamento, temos buscado compreender e intervir nas condições de vulnerabilidade de famílias que vivenciam a experiência de alcoolismo na família ${ }^{7}$.

Ao realizarmos a avaliação e intervenção na família, tem-se utilizado o referencial do Modelo Calgary de Avaliação e Intervenção na Família ${ }^{8}$. Ele utiliza, na avaliação estrutural da família, os instrumentos Genograma e Ecomapa, que possibilitam a compreensão da estrutura da família, de suas relações internas e com o contexto e os recursos sociais de apoio que utiliza para enfrentar suas condições de vulnerabilidade. 0 Genograma tem sido amplamente utilizado em estudos com famílias que enfrentam diferentes problemas, em diferentes abordagens metodológicas e referenciais teóricos. Alguns autores o utilizam na terapia sistêmica de família de alcoolistas e o recomendam no trabalho com familias que enfrentam esse problema ${ }^{9}$.

Diante do exposto, apresenta-se neste artigo a experiência na avaliação de famílias de usuários de álcool adstritas a uma Unidade do Programa de Saúde da Família (PSF) de um município do interior de São Paulo. A escolha por trabalhar com famílias de uma Unidade de Saúde da Família (USF) aconteceu em função de a família constituir-se em um novo modelo de atenção em saúde tornando-se objeto do cuidado. Dessa forma, esta pesquisa vai ao encontro das diretrizes do Ministério da Saúde, em sua política de atenção aos usuários de álcool e outras drogas no âmbito do SUS. Essa política foi instituída através do Programa Nacional de Atenção Comunitária Integrada aos usuários de Álcool e outras Drogas enfatizando a estruturação e o fortalecimento de uma rede de assistência centrada na atenção comunitária associada à rede de serviços de saúde e sociais'.

Assim sendo, este trabalho teve como objetivo compreender 0 alcoolismo na família através da identificação da estrutura e das relações familiares, da rede de suporte social da família e da vivência dessas famílias.

\section{METODOLOGIA}

Este estudo insere-se nos pressupostos do método qualitativo de investigação.

A pesquisa qualitativa trabalha com universo de significados, motivos, aspirações, crenças, valores e atitudes, o que corresponde a um espaço mais profundo das relações, dos processos dos fenômenos que não podem ser reduzidos à operacionalização de variáveis ${ }^{10: 105}$. 


\section{Operacionalização, técnica de coleta de dados, análise e apresentação dos resultados}

Conforme afirmado, pautamo-nos nesta pesquisa na avaliação estrutural descrita no Modelo Calgary de Avaliação da Família (MCAF), realizada através de entrevista com a família?.

\section{Sujeitos da pesquisa}

Os membros de cinco famílias de usuários de álcool foram sujeitos desta pesquisa. Essas familias foram indicadas pelos agentes comunitários de uma USF, na cidade de São Carlos.

Inicialmente, houve planejamento para realizar a entrevista com todos os membros da família, incluindo o usuário de álcool. Porém, elas ocorreram sem a presença desse familiar, uma vez que as famílias não se dispuseram a incluí-lo alegando que se sentiriam constrangidas em sua presença. Elas também ocorreram com, no máximo, dois membros de cada família, uma vez que foram esses que se disponibilizaram. 0 quadro abaixo relaciona o total de entrevistados por família e o parentesco em relação ao(s) membro(os) alcoolista(s) das famílias (Quadro 1).

\section{Entrevista (roteiro, tempo de duração, local, anotação e análise dos dados)}

As entrevistas foram semi-estruturadas. Portanto, 0 entrevistador dispôs de um roteiro de entrevista de forma a orientar os dados a serem coletados. Esse roteiro era composto de duas partes: a primeira compreendia questões de forma a levantar a estrutura, o contexto e a rede de suporte social da familia, ou seja, compreendia a construção do genograma e ecomapa junto com a familia. A segunda, continha questões abertas relativas às vivências da familia diante do alcoolismo.

0 tempo de duração das entrevistas foi de no máximo uma hora e trinta minutos. Elas ocorreram tanto no domicilio como na própria USF, sendo gravadas em fita magnética cassete, em áudio após a assinatura do Termo de Consentimento Livre e Esclarecido.

A pesquisa foi aprovada pelo Comitê de Ética em Pesquisa da instituição onde o trabalho foi desenvolvido. Os nomes dos entrevistados foram substituídos por outros nomes para garantir o sigilo e 0 anonimato dos participantes.

De posse dos dados, primeiramente, construímos os genogramas e ecomapas das famílias. A análise dos dados referentes à vivência da família se deu através da análise de conteúdo" ${ }^{11}$.

QUADRO 1:

Número de membros entrevistados de cada família e grau de parentesco em relação ao(s) usuário(s) de álcool.

\begin{tabular}{|l|c|c|c|}
\hline Família* & $\begin{array}{c}\text { Número de } \\
\text { entrevistados }\end{array}$ & $\begin{array}{c}\text { Número de usuários } \\
\text { de álcool na } \\
\text { Família e relação } \\
\text { de parentesco } \\
\text { com o entrevistado }\end{array}$ & $\begin{array}{c}\text { Parentesco do } \\
\text { entrevistado } \\
\text { em relação ao(s) } \\
\text { usuários de álcool }\end{array}$ \\
\hline Família 1 & 1 & 1 (marido) & $\begin{array}{c}\text { Esposa } \\
\text { Família 2 }\end{array}$ \\
Família 3 & 2 & 1 (marido e filho) \\
Família 4 & 2 & 1 (filho e enteado) & Esposa/mãe e filha/irmã \\
Família 5 & 1 & 9 (marido e filho) & Mãe e padrasto \\
Esposa/mãe
\end{tabular}

*As famílias entrevistadas foram identificadas de um a cinco

\section{RESULTADOS E DISCUSSÃO}

Primeiramente são apresentados os dados relativos à estrutura, às relações e a rede de apoio social das famílias, obtidos através dos Genogramas e Ecomapas (Figuras 1,2,3,4,5). Em seguida, os dados da vivência das famílias entrevistadas diante do alcoolismo na família.

\section{A estrutura, as relações e a rede de apoio social das famílias}

\section{Família 1}

Ana (32) é casada com Edilson (33) há 11 anos e mora com ele e seus 4 filhos Caio (11), Pedro (10),
Renato (8) e Daniel (4) em uma casa bastante simples de 2 cômodos, sem reboco e inacabada. Ela revela que o marido faz uso de bebida alcoólica há alguns anos com bastante freqüência e que o uso do álcool se iniciou por influência dos amigos de trabalho. A família precisou mudar de bairro, segundo Ana, devido a dívidas que 0 marido contraía em bares e não conseguia pagar. A família mora no bairro atual há cinco anos. Ana relata que, na maioria das vezes, o marido chega em casa embriagado e se torna agressivo com ela e com as crianças. Apesar de a família possuir vínculos fortes entre si, percebe-se que os conflitos, devido ao alcoolismo, são constantes. Ana conta que foi agredida 
várias vezes e que houve momentos em que as crianças pediam para sair de casa por sentirem-se ameaçadas.

\section{Família 2}

Márcia (67) e Moacir (59) moram há 14 anos em uma casa simples. 0 filho mais novo, Jorge (25), casado e pai de duas meninas (seis e sete anos), mora, também, na casa de seus pais, devido à dificuldade financeira. A família veio do Paraná em busca de melhores condições de vida e trabalho. Márcia trabalhou muitos anos "na roça" e, hoje, é aposentada. Seu marido Moacir trabalhou em muitas empresas, porém, devido à saúde debilitada

Figura 1: Genograma e Ecomapa da Família 1

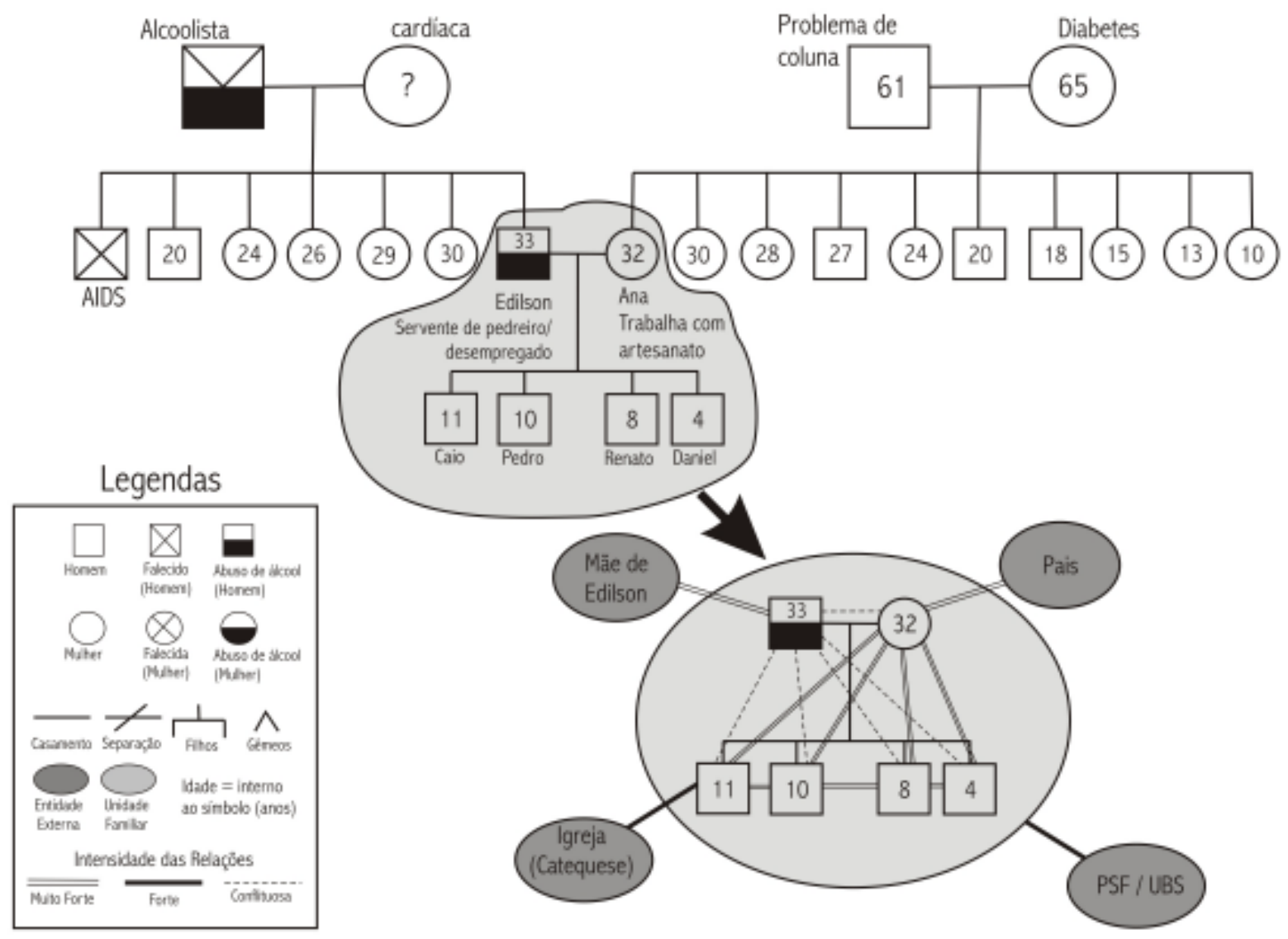

e ao problema do alcoolismo, está, há algum tempo, fazendo "bicos" como servente de pedreiro.

Larissa (29), a filha mais velha, mora com seu filho (10) na casa em frente à de sua família. Percebemos que ela se preocupa muito com a dependência de álcool que seu pai apresenta. Relata que muitas vezes tentou ajudá-lo conversando, procurando recursos de apoio, porém acredita que sozinha não conseguirá livrar o pai da dependência.

\section{Família 3}

Joana (49) e Carlos (41) são casados há 19 anos. Moram numa casa própria, com 5 cômodos, apresentando boas condições de higiene. Eles moravam em São Paulo e migraram para São Carlos há alguns anos para ficarem mais perto da filha de Joana. Junto com eles, mora D. Antonieta (74), mãe de
Joana. No momento da entrevista, realizada no próprio domicílio, estavam presentes Joana e D. Antonieta.

Observamos que Joana estava bastante nervosa e preocupada com o futuro de seu casamento por causa do problema do alcoolismo do marido, mostrando-se até um pouco desorientada no dia em que a visitamos, inclusive dizendo que a única solução para melhorar sua vida seria se separar de Carlos. Percebemos que a maior objeção a uma possível separação era o fato dela ser muito religiosa e acreditar que não deveria fazer isso por causa das "leis de Deus". Entretanto, em outros momentos ela afirma que ama o marido.

\section{Família 4}

Sr. João (73) e D. Maria (75) moram juntos numa casa própria, simples, com 4 cômodos, apresentando boas condições de higiene. 0 filho dela, do primeiro casamento, Ronaldo (42), solteiro, 
Figura 2: Genograma e Ecomapa da Família 2

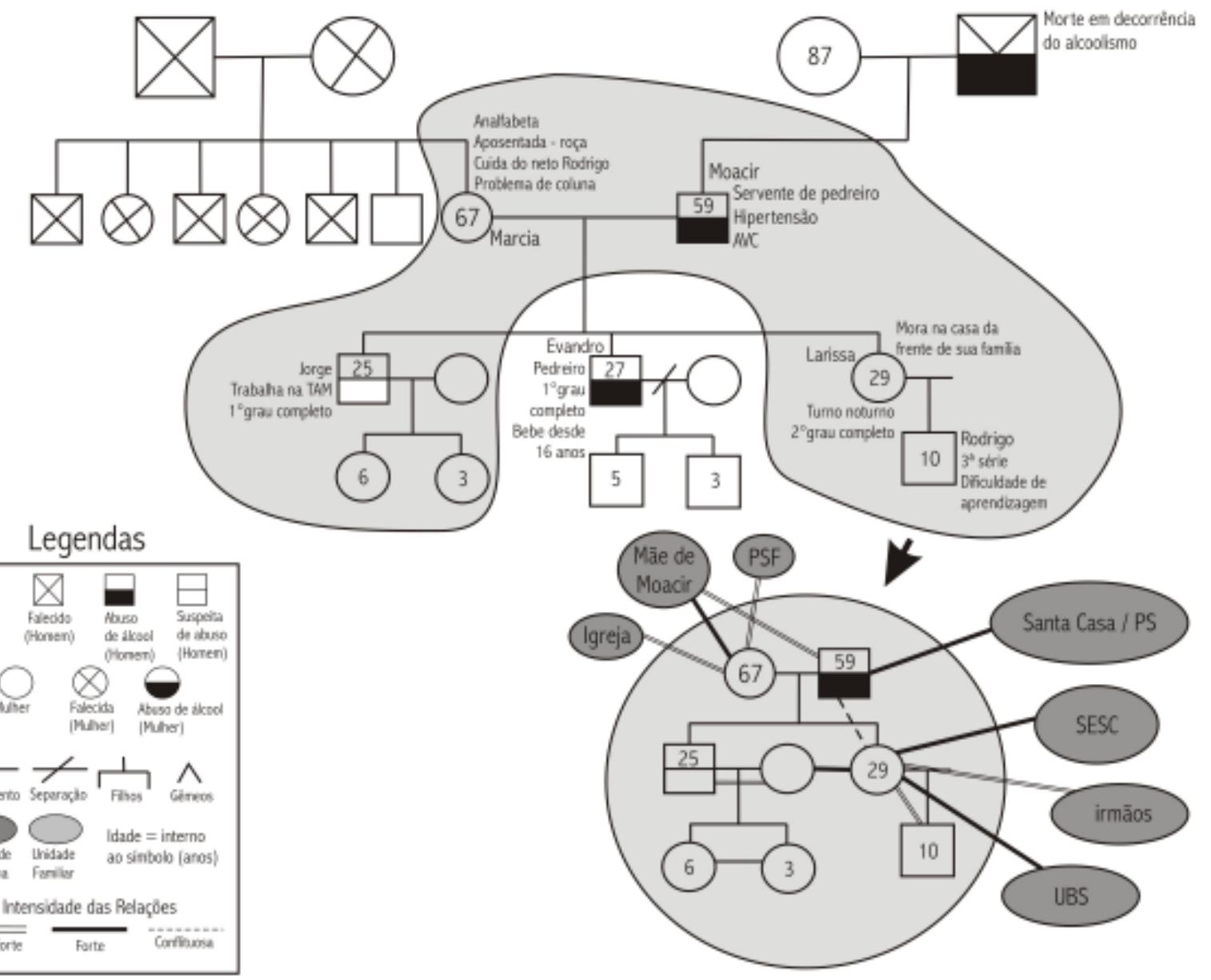

Figura 3: Genograma e Ecomapa da Família 3

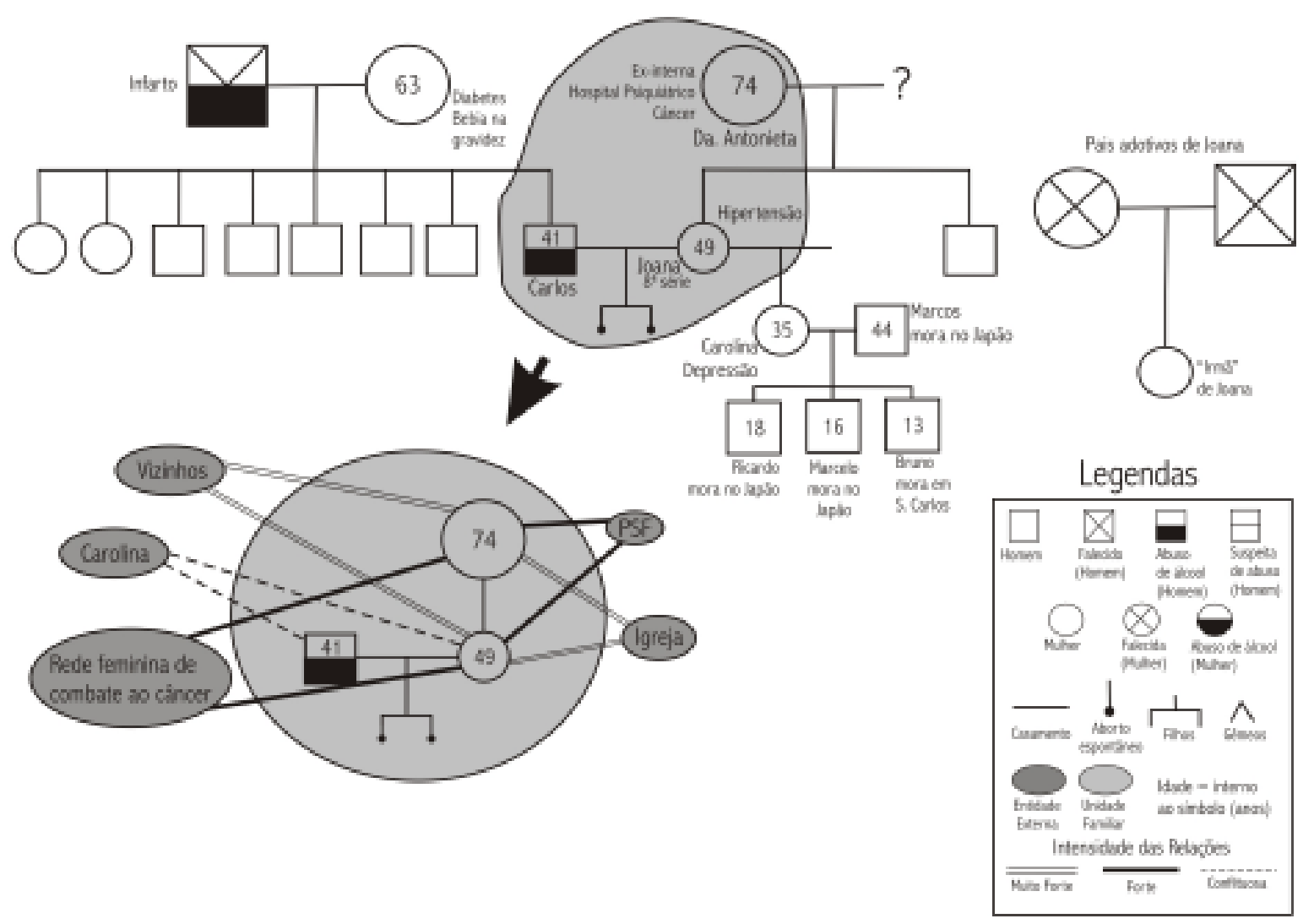


mora com eles e nos foi indicado pela agente de saúde como sendo alcoolista.

Na primeira entrevista, realizada no próprio domicílio, conversamos com D. Maria e Sr. João. D. Maria contounos que Ronaldo estava trabalhando na colheita da laranja e que o uso de álcool do filho era um problema. 0 casal demonstrou certo alívio por Ronaldo ter começado a trabalhar (o dia da entrevista era o primeiro dia de um novo serviço) porque afirmaram que Ronaldo diminuiu a ingestão de álcool. Entretanto, percebemos, também, na primeira visita, que Sr. João e D. Maria convivem com o uso abusivo de álcool de Ronaldo.

Família 5

Dona Marta (64) e Sr. João (70) são casados há 47 anos e moram numa casa simples sem acabamento. Tiveram doze filhos, dez estão vivos e dois morreram (um com dezoito dias e outro com cinco dias). Entre os filhos vivos, moram com o casal Cláudio (39), Edson (36), Flávio (34) e Bruno (28) que são solteiros e alcoolistas como o pai.

Arnaldo (44), Carla (43), Osvaldo (41), Cecília (40), Emerson (38) e Wagner (30) são casados e moram com suas respectivas famílias, exceto Osvaldo que, apesar de ser casado, está desempregado e está vivendo temporariamente na casa de seus pais, pois sua esposa fica mais na casa de sua mãe do que na casa adquirida por eles.

Segundo Dona Marta, todos os filhos homens, casados, também já apresentaram problemas com a bebida no passado, porém se recuperaram. Contudo, Osvaldo, devido sua atual situação, vem apresentando uma recaída.
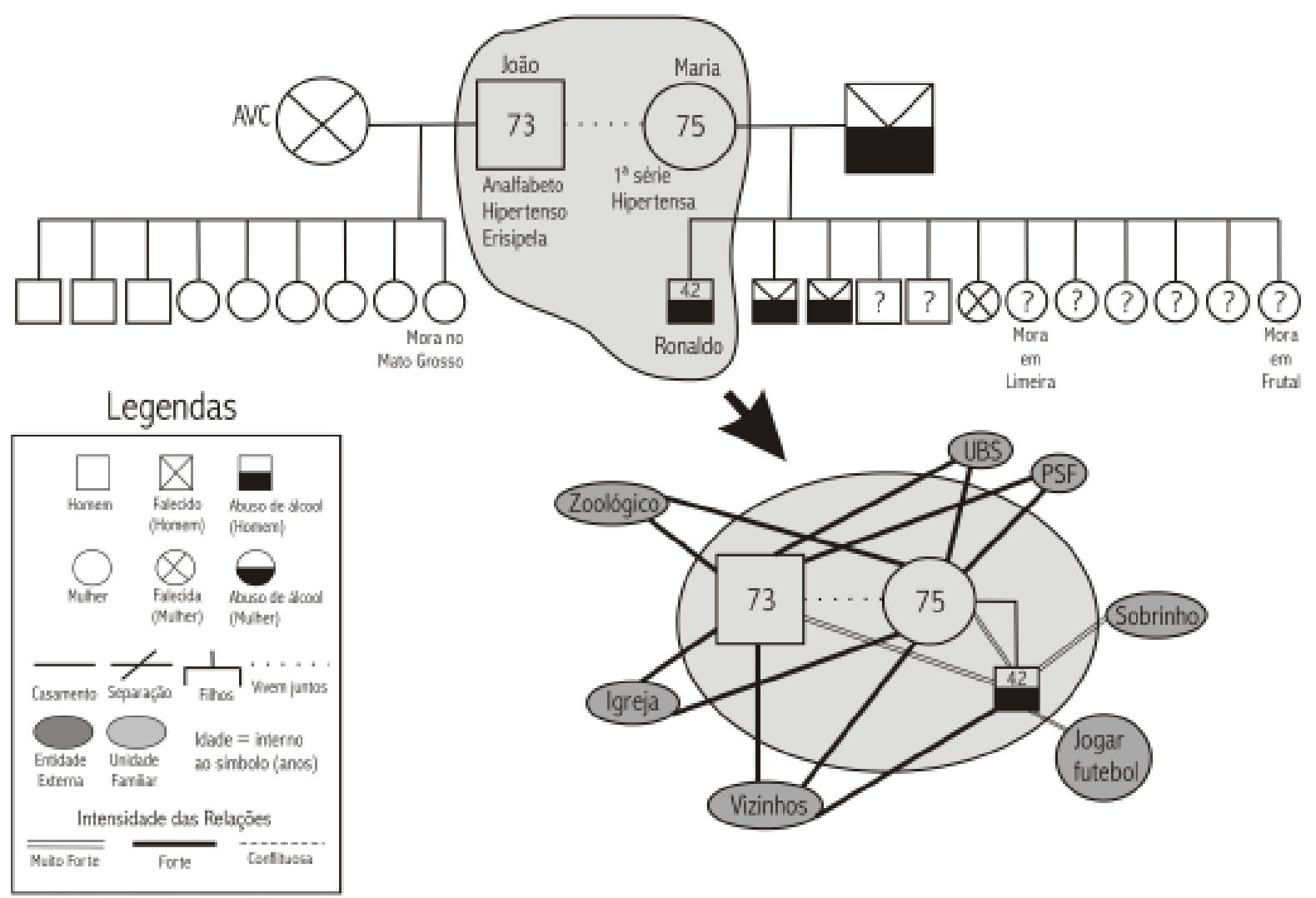


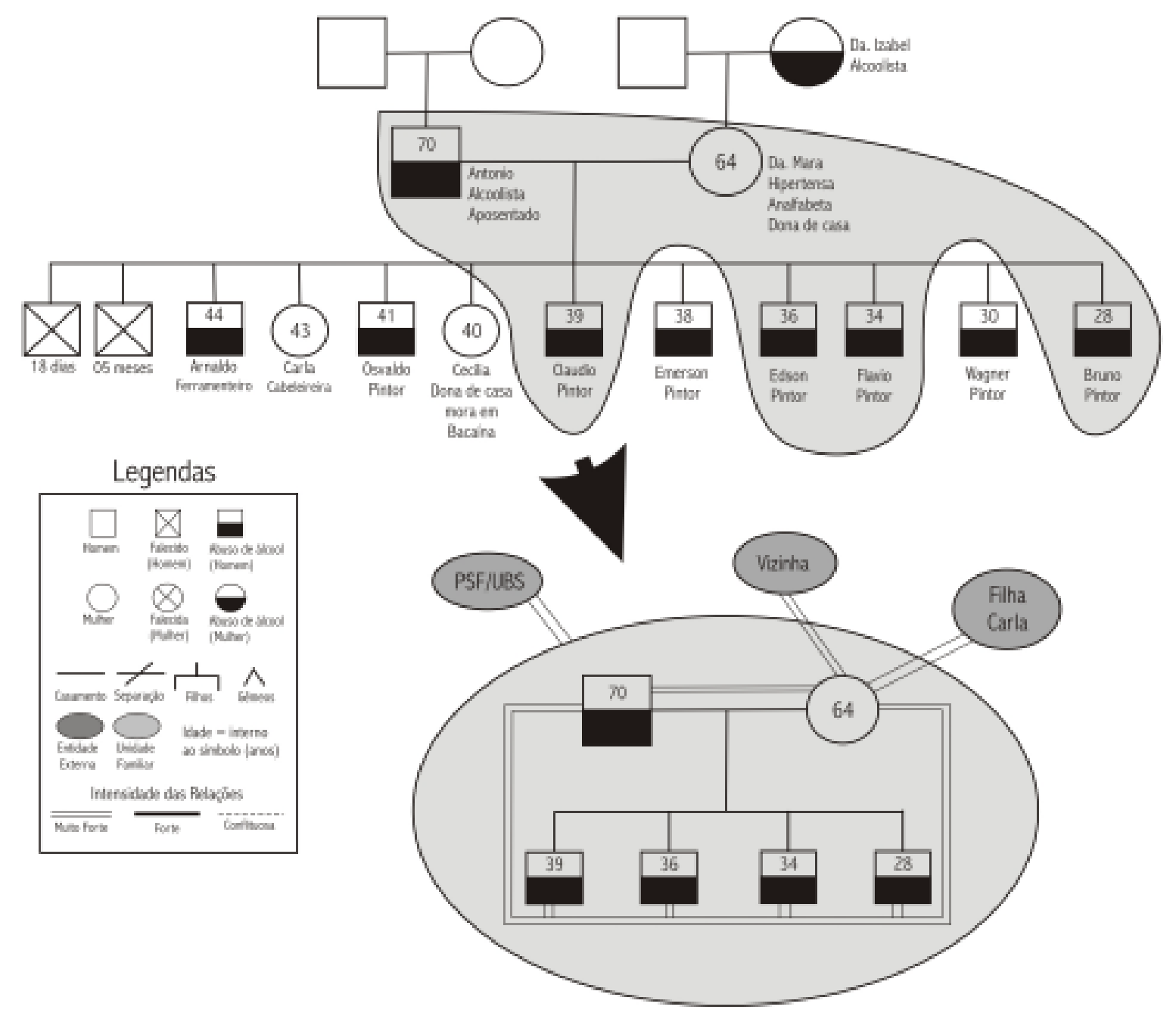

\section{Compreendendo a vivência da família diante do alcoolismo}

A partir da análise dos dados referentes à vivência das famílias foram criadas cinco categorias: 1 - 0s problemas enfrentados pelas famílias; 2 - 0 conhecimento sobre o alcoolismo; 3 - 0 sofrimento diante do alcoolismo e as relações familiares; 4 - As dificuldades dos familiares em relação ao alcoolismo e 5 - A rede de apoio social à família.

\section{Categoria 1}

Os problemas enfrentados pelas famílias

Ao analisar os problemas enfrentados pelas famílias, verifica-se que, embora apresentem dificuldades financeiras, o alcoolismo constituiu-se no maior problema para a maioria.

0 único problema que eu tava enfrentando era a bebedeira dele. E graças a Deus que ele diminuiu bem. Não sei o que aconteceu com ele. Se foi também o que aconteceu com o irmão dele. Acho que ele sentiu, né. Aí ele maneirou bem. De primeiro era garrafa de pinga dentro de casa. Ele me batia, me espancava. Mas graças a Deus tá parando com tudo isso. (Ana - Família 1)

0 problema maior é esse. A bebida. Se não é meu marido, é meu filho. (Márcia - Família 2)

As famílias também se referiram a outros problemas, tais como: o uso de outros tipos de drogas além do álcool, a falta de apoio de outros membros da família, a falta de contato com outros ou demais membros da família e, finalmente, os problemas financeiros.

\section{Categoria 2}

\section{o conhecimento sobre o al coolismo}

Verificamos que as famílias demonstram pouco conhecimento sobre o alcoolismo, desconhecendo conceitos importantes para a compreensão deste problema de saúde e do seu tratamento. Há uma familiar que reconhece que não sabe nada:

Sinceramente nada. Só sei que chega uma época que o organismo não agüenta mais. Como aconteceu com meu sogro. Chegou uma época, 
ele trabalhava muito bem, na Lápis. Aí depois se aposentou começou a beber, beber e chegou um tempo ele que tava dormindo na rua e a gente precisava buscar ele. Aí chegou uma época que ele não tava mais agüentando. Até álcool puro ele tava bebendo. Nem a bebida tava mais satisfazendo ele. (Ana - Família 1)

Outra, embora reconheça que o alcoolismo é uma doença, desconfia que a pessoa faz uso da doença em proveito próprio, sendo o alcoolismo uma forma de se acomodar.

Olha, eu tenho certeza que é uma dependência, mas tem momentos que, como se fala, tem aquela pessoa que quer se aproveitar da situação, também. (Joana - Família 3)

Há também uma família que considera que quem faz uso do álcool, mas continua realizando seu trabalho não é um alcoolista.

...ele bebe pinga, mas continua trabalhando. (Da. Maria - Família 4)

Outras famílias desconhecem os determinantes do alcoolismo acreditando que a pessoa já nasce alcoolista ou que a pessoa torna-se alcoolista por vontade própria, desconhecendo ainda que a recaída faz parte do problema.

É a mãe dele fala que, ele até brinca: 'Esse aí já bebia quando tava dentro da minha barriga.' Eu achava tão triste ela falar... (Joana - Família 3)

Ele ficou um tempo sem beber, mas agora voltou... Eu não tenho a mínima idéia do porque ele voltou a beber. De repente ele apareceu aqui bêbado. Eu imaginei que nunca mais ele fosse beber. (Larissa - Família 2)

Há uma familiar que não sabe discorrer sobre a doença, mas sabe que o alcoolismo prejudica a saúde levando à morte.

0 alcoolismo, a pessoa alcoólica não tem saúde, porque o vício de beber é uma coisa que mata, né? Quantas pessoa que eu já escutei falar que morreu de tanto beber. É uma coisa incrível não pode. $A$ bebida mata a pessoa. (Da. Marta - Família 5)

0 reconhecimento do alcoolismo como doença representa uma dificuldade tanto para as famílias como para a sociedade. A idéia do alcoolismo como doença surge no século XIX quando passa a ser considerado um problema de saúde pública ${ }^{3}$.

0 conceito de doença do alcoolismo foi proposto a partir de pesquisas clínicas incluindo o indivíduo e o seu ambiente, sendo reconhecido pela Organização Mundial de Saúde como uma patologia e, mais recentemente, como Síndrome da Dependência do Álcool ${ }^{12}$.
Um outro fator de dificuldade do reconhecimento do alcoolismo como doença é o fato da ingestão de bebidas alcoólicas levar a quadros muito diferentes com cursos irregulares e prognósticos variáveis ${ }^{12}$.

\section{Categoria 3}

O sofrimento diante do al cool ismo

e as relações familiares

0 sofrimento das famílias em ter um familiar alcoolista é muito grande, na maioria dos casos. A fala de uma familiar sobre o que é o alcoolismo na família ilustra o que realmente representa isso para as famílias, ou seja: só quem passa é que sabe. Verificamos que, quando há a presença de violência, o sofrimento é ainda maior:

Um desastre! Porque só quem passa por isso dentro de casa que sabe, né?. Eu já apanhei muito. Uma vez ele tava bêbado, e ele fica tão irritado que muda, parece que tem outra pessoa. Não é ele. Chegou a derrubar o armário inteiro com lata de arroz, feijão. Minha geladeira ele virou, jogou tudo que tinha dentro pro cachorro. Eu sei que foi um inferno! Mas agora não tem nem comparação. (Ana - Família 1)

A violência sofrida pelos familiares e suas repercussões para os filhos (crianças com dificuldades na fala, de aprendizagem e relacionamento) são algumas das dificuldades enfrentadas pela família. Também estão presente a frustração e o desgaste emocional diante da constante busca em convencer 0 familiar a se tratar, uma vez que poucos aceitaram algum tipo de ajuda, ao longo dos anos. Ainda revelaram forte sentimento de vergonha em relação ao familiar alcoolista devido a suas atitudes constrangedoras e comprometedoras da vida social das mesmas.

É chato, né, menina. Porque você não pode ir em nenhuma festa de medo de ele beber, ou bater até na frente dos outros ele é capaz, de xingar. $E$ vergonhoso. Os outros ficam vendo ele bebendo. (Ana - Família 1)

Ele fica gritando, quebrando as coisas, falando palavrão. Outro dia a Amanda, lá do Projeto veio aqui. Eu morri de vergonha da Amanda. Ela veio aqui e começou a conversar e ele veio $e$ começou a me chamar de minha filha. Aí eu falei pra Amanda: 'Me desculpa Amanda, mas este senhor é assim mesmo. Todo mundo que ele conhece, ele chama de filha..' É uma coisa muito feia. (Larissa - Família 2)

Ao analisar as relações familiares, constatamos que elas são, na maioria das vezes, conturbadas, principalmente quando eles estão alcoolizados. Três esposas entrevistadas sofreram agressões físicas. Elas 
vivem considerando a separação como uma das formas de solução do problema. Há, também, uma grande preocupação com os filhos, quando eles ainda são menores de idade.

Porque ele tava me batendo, me batendo e eu tinha medo de ele me machucar, eu reagir e ele me machucar porque eu pensava nas crianças.(Ana - Família 1)

Em consequência do alcoolismo, os filhos afastamse dos pais alcoolistas por medo e vergonha. Também existe 0 isolamento da família.

...é diferente de antes, porque antes, todo dia, eles, minhas cunhadas vinham aqui e deixavam as crianças. Mas agora, o dia que ele bebe, elas não deixam mais. Pedem pra eles [crianças] ficarem na creche. (Larissa - Família 2)

\section{Categoria 4}

As dificul dades dos familiares

em relação ao alcoolismo

Ao analisar as dificuldades das famílias frente ao alcoolismo, encontra-se a violência sofrida pelos familiares como o mais grave dos problemas:

Não, ele tinha parado porque eu aprendi a bater também. Porque ele tava me batendo, me batendo e eu tinha medo de ele me machucar. (Ana - Família 1)

A essa altura já passei por problemas do lado moral...Ah, eu não sei explicar...Então, a vergonha de alguém, se ele tem que fazer ele faz. (Joana - Família 3)

Uma outra grande dificuldade é a repercussão nos filhos menores, porque são muito afetados. Uma mãe relata que eles ficam amedrontados, nervosos, têm dificuldades na escola e na vida pessoal.

Teve uma época que meus moleques tavam indo ruim na escola. Aí a professora me chamava e eu abri o jogo com ela. Aí elas começaram a lidar com eles diferente dos outros, porque elas tavam vendo que o negócio em casa tava prejudicando eles na escola. Tanto é que eu tenho um moleque que nem fala direito. Ele fala tudo enrolado este de 8 anos. Ele não fala direito, ele precisa de fono. Mas como é corrido. (Ana - Família 1)

Outras repercussões são o nervosismo e a insônia, pois os familiares preocupam-se e não sabem como lidar com a situação. Além disso, existe a dificuldade em lidar com atitudes do familiar consideradas imorais, tais como o roubo de dinheiro para o uso com bebidas.

É muita dificuldade. Tem dia que a gente não dorme, fica preocupada. (Márcia - Família 2)
Não, ele pegava, mesmo...Até que eu passei pra minha mãe guardar. Até que ele começou a revirar as gavetas dela, também. E aí, num dá. Então, deixa lá, recebe, paga o que tem que pagar, compra passe e vem embora. (Joana - Família 3)

Os familiares ainda enfrentam a recusa na realização de outros tratamentos médicos reforçando o uso do álcool:

Ele não quer beber, não toma o remédio da pressão... Ele fala: Péra aí, que eu já sei qual é o meu remédio pra ela abaixar. Vai lá e toma duas pingas. (Da. Marta - Família 5)

Além de tudo isso, a mesma familiar queixa-se da sua relação conjugal, da vida marido/mulher.

Eu tô sofrendo filha, nessas parte eu tô sofrendo. À noite eu quero dormi e falo: eu já tive doze filhos com você e... que você quer mais? Então, já que você gosta da sua pinga, então você fica com a sua pinga e eu fico descansando! Porque agora, eu tô velha eu quero descansar. (Da. Marta - Família 5)

Atualmente existe uma grande preocupação sobre as diferentes formas de violência doméstica, bem como suas relações com o uso, abuso e dependência do álcool uma vez que esse vem crescendo entre a população. Tais problemáticas não afetam apenas os casais, mas crianças e adolescentes, comprometendo o bem estar físico e psicológico da família ${ }^{12}$.

Diante desses resultados consideramos que a rede de apoio social seria de fundamental importância para essas famílias.

\section{Categoria 5}

A rede de apoio social à família

A rede social é um sistema composto por vários objetos sociais (pessoas), funções (atividades dessas pessoas) e situações (contexto), que oferece apoio instrumental e emocional à pessoa, em suas diferentes necessidades ${ }^{13}$. Apoio instrumental é entendido como ajuda financeira, ajuda na divisão de responsabilidades em geral e informação prestada ao indivíduo. Apoio emocional, por sua vez, refere-se à afeição, aprovação, simpatia e preocupação com o outro e, também, a ações que levam a um sentimento de pertencer ao grupo.

Entre os recursos oferecidos destacam-se as redes de saúde, as agências sociais, as instituições civis, as associações familiares, os centros comunitários, grupos de cultura, educação, lazer e esporte. Os grupos têm como principal objetivo o fortalecimento da auto-estima, da criatividade, da independência, da autonomia e da socialização, favorecendo um caráter sócial interativo ${ }^{14}$. $\mathrm{Na}$ área do alcoolismo, identificam-se os grupos de 
auto-ajuda AL-Anon e Alateen (para familiares e filhos de alcoolistas, respectivamente) como importantes fontes de apoio à família.

Os recursos sociais de apoio entre os serviços de saúde que as famílias entrevistadas mais utilizam é a Unidade de Saúde da Família. Assim falam:

A gente procura o médico, o posto. 0 posto aqui e aquele lá de cima. (Ana - Família 1)

Eu uso o postinho família, pronto socorro, Santa Casa. (Larissa - Família 2)

...Olha gente, abaixo de Deus pra mim, essa turma, essa equipe é o anjo de Deus na terra. (Joana - Família 3)

Aí eu peguei meu marido, arrumo um carro. Aí eu fui lá no postinho, lá em cima. (Da. Marta - Família 5)

Portanto, constata-se que a maioria das famílias, quando questionadas sobre os recursos que utilizam, não citou uso de quaisquer recursos, seja da saúde ou de grupos de apoio para ajudá-las no enfrentamento do alcoolismo. Esses dados tornam-se preocupantes uma vez que estudos têm assinalado a importância da rede social e do apoio social como elementos significativos na manutenção da saúde ${ }^{15}$.

\section{CONSIDERAÇÕES FINAIS}

Ao considerar o que nossa aproximação às famílias de alcoolistas trouxe, deve-se assinalar primeiramente o enorme sofrimento e as sérias repercussões que esse problema traz para a família, o que nos leva à reafirmação de que este é um grave problema de saúde que deve ser enfrentado pela sociedade.

Ao analisar os problemas que as famílias vêm enfrentando, verifica-se que, embora elas apresentem dificuldades financeiras, o alcoolismo constitui-se no maior problema para a maioria delas, afetando toda a família, o que vem reforçar os achados encontrados na literatura.

As famílias também demonstraram pouco conhecimento sobre o alcoolismo, desconhecendo

\section{Referências}

1. Ministério da Saúde (BR). Secretaria de Atenção à Saúde. SVS/CN/ DST/AIDS. A política do Ministério da Saúde para a atenção integral a usuários de álcool e outras drogas. Brasília (DF); 2004.

2. Carlini EA et al. I Levantamento domiciliar sobre o uso de drogas psicotrópicas no Brasil: estudo envolvendo as 107 maiores cidades do país: 2001. [on line] [citado 18 abr 2004]. Disponível em: http:/ /www.cebrid.epm.br/levantamento_brasil/parte_1.pdf

3. Laranjeira R, Pinsky I. 0 alcoolismo. São Paulo (SP): Contexto; 1998. conceitos importantes para a compreensão desta doença/síndrome e de seu tratamento, o que leva à identificação da necessidade de receberem maiores informações sobre o alcoolismo e o seu tratamento.

Quanto às relações familiares, verifica-se que elas são, na maioria das vezes, conturbadas. Os filhos afastam-se dos pais alcoolistas por medo e vergonha, algumas esposas estão sempre considerando a possibilidade de separação como única forma de solucionar o problema, relatando também que há prejuízos para a vida conjugal. Ainda constata-se que a maioria das famílias evita falar do alcoolismo com os demais familiares isolando-se diante do problema. Os familiares revelaram também um forte sentimento de vergonha em relação ao familiar alcoolista devido a suas atitudes constrangedoras, o que compromete sobremaneira a vida social das mesmas.

Entre as maiores dificuldades enfrentadas pela família encontra-se a violência sofrida pelos familiares e suas repercussões sobre os filhos. Também estão presentes a frustração e o desgaste emocional diante da constante busca em convencer o familiar a fazer o tratamento uma vez que poucos aceitaram algum tipo de ajuda, ao longo dos anos, e nenhum se encontrava em tratamento.

Diante desses resultados, a rede de apoio social seria de fundamental importância para essas famílias. Entretanto, ao se analisar a situação da rede de saúde, encontra-se a precariedade de recursos públicos de saúde na área de atenção ao alcoolismo no município em questão ${ }^{16}$, o desconhecimento das famílias sobre os recursos existentes e a não utilização dos Grupos de Apoio para famílias e filhos de alcoolistas (Al-Anon e Alateen).

Ainda em relação à rede de saúde, a Unidade de Saúde da Família é o recurso de saúde mais utilizado pelas famílias, o que leva ao seu reconhecimento como uma importante estratégia no enfrentamento do alcoolismo. Finalmente, cabe indagar como o Programa de Saúde da Família tem trabalhado com o alcoolismo na família. Certamente essa é uma questão que necessita ser analisada mais detidamente, em futuras investigações.

4. Hill E, Gauer G, Gomes WB. Uma análise semiótico-fenomenológica das mensagens auto-reflexivas de filhos adultos de alcoolistas. Psicologia: reflexão e crítica. [on line] 1998; [citado 09 ago 2006]; 11(1). Disponível em: http://www.scielo.br/scielo.php?script=sci_arttext\&pid

5. Buchele F, Marcatti M, Rabelo DR. Dependência química e prevenção à "recaída". Texto \& Contexto Enferm 2004; 1(1): 233-40.

6. Martins ACC, Pillon SC, Luis MAV. A família e sua importância a dependentes de substâncias psicoativas. In: Luis MAV, Pillon SC, organizadores. Assistência a usuários de álcool e drogas no estado de São Paulo: uma amostra de serviços e programas. Ribeirão Preto (SP): FIERP; 2004. p. 216-28. 
7. Nascimento MMA, Silva HF, Filizola CLA, Peron CJ. Intervindo junto a famílias de alcoolistas de um PSF do município de São Carlos. Resumos dos trabalhos apresentados no $8^{\circ}$ Encontro de Pesquisadores em Saúde Mental. $7^{\circ}$ Encontro de Especialistas em Enfermagem Psiquiátrica; 2004 abr 5-8; Ribeirão Preto (SP), Brasil. Ribeirão Preto (SP): EERP; 2004. p. 215.

8. Whight LM, Leahey M. Enfermeiras e famílias: um guia para avaliação e intervenção na família. São Paulo (SP): Roca; 2002.

9. Zuse AS, Rossato VMD, Backes, VMS. Genetograma: um instrumento de trabalho na compreensão sistêmica de vida. Rev Latino-Am Enfermagem 2002 maio/jun; 10 (3): 308-20.

10. Minayo MCS. 0 desafio do conhecimento: pesquisa qualitativa em saúde. São Paulo (SP):Hucitec/ ABRASCO; 1992.

11. Bardin L. Análise de conteúdo. São Paulo (SP): Ed 70; 1977.

12. Pinto EF, Pillon SC. Alcoolismo e violência doméstica. In: Luis MAV, Pillon SC, organizadores. Pesquisas sobre a prática da assistência a usuários de álcool e drogas no estado de São Paulo. Ribeirão Preto (SP): FIERP; 2004, p. 79-94.

13. Dessen MA, Braz MP. Rede social de apoio durante transições familiares decorrentes do nascimento de filhos. Psicologia: teoria e pesquisa 2000 set-dez; 16 (3): 7-14.

14. Varoto VAG. Equando a dependência chegar? [tese de doutorado]. São Carlos (SP): Departamento de Engenharia de Produção/UFSCar; 2005.

15. Griep RH. Confiabilidade e validade de instrumentos de medida de rede social e apoio social utilizados no estudo Pró-Saúde. [tese de doutorado]. Rio de Janeiro (RJ): Escola Nacional de Saúde Pública/FGV; 2003.
16. Tagliaferro P, Andrade AS, Filizola CLA. Rede de suporte social para famílias de usuários com transtorno mental do município de São Carlos. Resumos dos trabalhos apresentados no $13^{\circ}$ Simpósio Internacional de Iniciação Científica da USP-SIICUSP; 2005 nov 10-11; Ribeirão Preto (SP), Brasil. Ribeirão Preto (SP): USP; 2005. p.111.

\section{Sobre os Autores}

\section{Carmen Lúcia Alves Filizola}

Universidade Federal de São Carlos, São Carlos - SP

\section{Camila de Jesus Perón}

Universidade Federal de São Carlos, São Carlos - SP

\section{Mariana Montagner Augusto do Nascimento}

Universidade Federal de São Carlos, São Carlos - SP

\section{Sofia Cristina lost Pavarini}

Universidade Federal de São Carlos, São Carlos - SP

José Fernando Petrilli Filho

Universidade Federal de São Carlos, São Carlos - SP 